Note: This is an Accepted Manuscript of an article published by Taylor \& Francis in Emotional and Behavioural Difficulties on 06 May 2014, available online: http://www.tandfonline.com/10.1080/13632752.2014.913760 or http://dx.doi.org/10.1080/13632752.2014.913760.

Citation: Maras, P.F., Moon, A. and Gridley, N. (2014) Attribution style of adolescents with school-reported social, emotional and behavioural difficulties. Emotional and Behavioural Difficulties, 19 (4). pp. 426-439. ISSN 1363-2752 (Print), 1741-2692 (Online) (doi:10.1080/13632752.2014.913760) 


\section{Attribution style of adolescents with school reported social, emotional and behavioural difficulties}

P. F. Maras ${ }^{1}$, A. Moon $^{2}, \&$ N. Gridley ${ }^{3}$

${ }^{1}$ Research Centre for Children Schools and Families, Department of Psychology, Social Work and Counselling, University of Greenwich, Avery Hill Campus, Southwood Site, Avery Hill Road, Eltham, London, SE9 2UG.

Tel No. 02083319627

Email: p.f.maras@gre.ac.uk

${ }^{2}$ Research Centre for Children Schools and Families, Department of Psychology, Social Work and Counselling, University of Greenwich, Avery Hill Campus, Southwood Site, Avery Hill Road, Eltham, London, SE9 2UG.

Tel No. 0208387560

Email: $\underline{\text { A.Moon@gre.ac.uk }}$

${ }^{3}$ Research Centre for Children Schools and Families, Department of Psychology, Social Work and Counselling, University of Greenwich, Avery Hill Campus, Southwood Site, Avery Hill Road, Eltham, London, SE9 2UG.

Tel No. 0208387560

Email: N.Gridley@gre.ac.uk

Abstract Word Count $=142 / 150$

Main Text Word Count $=6659 / 8000$ including all tables/figures/references 


\begin{abstract}
The aim of the study was to investigate the relationships between attribution style and social emotional and behavioural difficulties (SEBDs), and to explore differences in attribution tendencies between adolescents with and without SEBDs. A total of 71 adolescents attending a school in London were recruited; 27 were receiving support for SEBDs from the behaviour and education support team at their school and 45 were recruited from the main school population. Participants completed the Children's Attribution Style Questionnaire and the Strengths and Difficulties Questionnaire. A multivariate ANOVA revealed that adolescents with SEBDs had a more negative attribution style, made more stable attributions of negative events and reported less internal attributions of positive events than students without SEBDs. Findings highlight the importance of cognitive factors in providing a basis for interventions intending to address young people's behaviour and cater for the heterogeneous nature of SEBDs.
\end{abstract}

Keywords: Attribution style, SEBDs, behaviour, adolescence, school 


\section{Introduction}

During a House of Commons meeting (2010) on the subject of behaviour and discipline in schools, there was an overwhelming consensus that the terms 'Social, Emotional and Behavioural Difficulties' (SEBDs) can be used to label a heterogeneous group of problems. With emphasis on the effects of such labelling rather than the emotional content or implications for the young people, schools can find themselves in a catch-twenty two, struggling to both manage classroom behaviour as well as nurture the students in their care. Research continues to illuminate the long-term effects of SEBDs, ranging from failing to progress as expected (Anderson, Kutash \& Duchnowski, 2001), to lower levels of academic attainment (Reid, Gonzalez, Nordness, Trout \& Epstein, 2004), co-morbidity with depression (Rowe, Maughan \& Eley, 2006) and increased psychological distress in adulthood (Buchanan, Flouri \& Ten Brinke, 2002). The short-term implications of risk to academic underachievement (McEvoy \& Welker, 2000) coupled with the longer-term implications of mental health problems and societal costs, suggest a need to find a more comprehensive approach to such difficulties. Due to the complex and pervasive nature of SEBD's a holistic approach to pupil's emotional and social well-being, emphasising positive mental health for all, has been advocated (Weare \& Gray, 2003). One area that may offer solutions for these seemingly disparate problems is the study of attribution style.

Since its genesis, attribution style has been used as both an explanatory tool and predictive model for understanding an individual's self-concept and their likely reactions under given circumstances. Seminal to this is the work of Abramson, Seligman and Teasdale (1978), who postulated a three dimensional approach to explaining negative affect and depression. Attribution style is the result of a reformulated theory of learned helplessness; a perceived inescapability of negative events that results in passive behaviour. Whilst learned helplessness attempted to explain negative affect, or emotional trauma, as a learnt behaviour acquired through repeated exposure to negative events which one could not escape from, attribution theory proposes that an individual's negative affect is the consequence of their perception of the cause of an event rather than the actual cause (Kee Tony, 2003; Abramson et al., 1978). Put simply, individuals have a tendency to apply a particular attribution style, negative or positive, when thinking about the cause of events.

According to Abramson et al.'s (1978) framework, attribution style is best understood as the interrelation between three dimensions; 1) internality-externality, 2) stability-instability and 3) global-specific. Internality-externality refers to how an individual explains events as a consequence of the individual (internal) or as a cause of the environment/situation (external). Stability-instability refers to how likely an individual perceives the cause of events as being constant across time (stable) or transient (unstable). Finally, the global-specific dimension relates to whether the individual perceives the cause of an event to occur across all situations (global) or be situation-specific (specific). Whilst this revised theory of learned helplessness is more aligned with the symptomology of depression and negative affect (sadness and pessimism) and co-insides with the accepted etiology of depression proposed by Beck (1967) the theory is not without criticism. Firstly, attribution theory is reductionist, assuming that the 
complex nature of negative affect or depression can be explained by applying simple labels to behaviours. Secondly, by applying these labels the theory assumes that all individuals can be treated the same without considering the social, cultural or environmental factors that contribute to an individual's attribution of cause. Despite these criticisms, attribution theory has proven fundamental to understanding an individual's self-concept. For example, an individual with a tendency to explain disadvantageous events as being due to internal, stable and global factors and positive events as a consequence of external, unstable and specific factors will exhibit a negative attribution style. On the other hand an individual with a positive attribution style may attribute advantageous events to internal, stable and global causes, and negative events to external, unstable and specific causes. Subsequently the reformulation of the learned helplessness theory has contributed to research advancements with evidence indicating that negative attribution style is associated with a loss of self-esteem (Weiner, 1979) and depression (Lau, Rijsdijk \& Eley, 2006) in adolescence (Gladstone \& Kaslow, 1995) and later in life (Hilsman \& Garber, 1995).

The link between negative attribution style and depression is now widely accepted and there is substantial evidence exploring the affects beyond direct emotion. For example, over the last 20 years negative attribution style has been linked to poor academic performance (Tremblay, Masse, Perron, Leblanc, Schwartzman \& Ledingham, 1992; Hinshaw, 1992; Arnold, 1997), reading difficulties, low expectancy for future success at reading and failure to persist at reading (Butkowsky \& Willows, 1980). Despite this, a recent study conducted in Croatia of 295 teenagers, aged 15 to 18, failed to find the support expected for this in educational settings (Kurtović, 2012). During the experimental task students were asked explicitly, via a questionnaire, whether the causes for a grade that represented success or failure to them were due to internal/external factors. When scores from the questionnaire were compared to the students' self-reported depression and self-esteem no significant correlation was found. The study was subject to some severe limitations in relation to applied settings. Most notably, the paradigm only allowed for a single time snapshot by asking about a single incident of failure which, by its' nature excludes the 'stability' dimension. On the other hand, when the stability dimension is included results closer to Abramson et al., (1978) theoretical frameworks are reported. A good example of this is the study by Kee Tony (2003) whereby the author found support for the notion that adolescents who attributed negative events to internal, stable and global causes, yet attributed positive events due to external, unstable and specific causes, were more likely to misbehave in school. When failure or negative events occur, it is suggested adolescents may react by attributing the cause to themselves. When they experience success, they may believe they had no influence on the outcome. At first glance such findings may appear contradictory. However, in light of Abramson et al.'s (1978) attribution framework this would be the logical outcome. As for internalisation of failure resulting in a perpetuating self-concept it must also persist over time. Students may easily have attributed this particular failure to a hypothetical decrease in effort (internal-unstable), or to a case of bad luck on the questions (external-unstable). According to Abramson et al. (1978) for a low self-concept, or helplessness to perpetuate, internalisation must be internal- stable, for example, a lack of ability in a specific area that persists over 
time. Such a theory supports the key findings of attribution style within an educational setting. Firstly, of more theoretical importance, to gain an accurate indication of whether internal attributions are correlated with a negative self-concept the persistence of these views within a school setting must also be measured. Secondly, that a negative attribution style may be vulnerability in regards to academic underachievement, which is often seen to be comorbid with behavioural problems (Tremblay, et al., 1992).

Indeed, researchers have found attribution style relates to particular types of behavioural problems. For example, Toth, Cicchetti and Kim (2002) found that a negative cognitive style could lead to frustration that manifests as aggression. Furthermore, Kee Tony (2003) demonstrated, using a sample of adolescents in Hong Kong, a positive correlation between negative attribution style and self-reported school discipline problems, such as foul language, bullying, habitual lateness, substance use, property damage, cheating and truancy. Regression analyses also indicated that a negative attribution style and an external locus of control predicted school discipline problems independent of other variables. Such findings have been replicated by those examining particular named difficulties, for example, the attributions of young people with attention deficit/hyperactivity disorder (AD/HD: Collett \& Gimpel, 2004). Results demonstrated that young people with AD/HD were less likely than their peers without $\mathrm{AD} / \mathrm{HD}$ to attribute positive events to internal, stable and global factors, suggesting that the young people with $\mathrm{AD} / \mathrm{HD}$ believed that good things were not of their own doing, were specific to the situation, and were likely to change in the future.

Given the relationships between attribution style and depression, and attribution style and behaviour, some researchers have sought to investigate the effects of cognitive styles on both variables to try to explain the high comorbidity between depression and antisocial behaviour. Using the revised Children's Attribution Style Questionnaire (CASQ-R; Thompson, Kaslow, Weiss \& Nolen-Hoeksema, 1998) Rowe et al. (2006) reported that attribution style accounted for the association between depression and specific aspects of antisocial behaviour i.e. oppositionality or delinquency. However, as noted by the authors the study suffered from some limitations, namely that the results relied upon self-reported measures of behavioural difficulties. As well as potentially inflating the associations between the variables the study did not take into account other, perhaps more objective, measures of behaviour i.e. teacher reports. Consequently, it is not possible to infer either the impact of such difficulties or the duration of such. As previously illustrated the elements of 'stability' and 'globality' are intrinsic to a persistent negative attribution style, therefore if these elements are not present in the behaviour element of the research design it seems stretched to suggest that a persistently disruptive pattern of behaviour is associated with a persistent attribution style. For this reason, it is essential that a study includes objective measures of behaviour, as well as subjective ones, and that a measure of the global impact of the problems is also present.

The relationship between emotions and behaviour, as explored by Rowe et al. (2006) are particularly interesting given that the labels of internalising or externalising problems are used frequently in the literature, and suggest two separate problems with no underlying 
shared cause. This view is often upheld by statistics purporting that behavioural problems (externalising) are most often reported as affecting boys, whilst emotional problems (internalising) affect girls (Hutchings, Williams \& Martin, 2011; Office for National Statistics, 2007; Webster-Stratton, 1996). However, Rowe's (2006) findings do provide evidence to support the idea that both problems may be expressions of a common negative attribution style. As such this may implicate, as other researchers have suggested (Maras, 1996; Norwich, Cooper \& Maras, 2002), that a clear-cut dichotomy between emotional and behavioural difficulties is misleading. SEBDs are complex and the term often encompasses a range of concerns including delinquency, emotional difficulties, behavioural difficulties, social problems, learning difficulties, and mental health problems (Maras, 1996; Norwich et al., 2002). Although the disruptive behaviour shown by some young people is obviously concerning, the internalisation of difficulties, which can manifest as depression, may go undetected, especially within the demanding school context. In busy school environments, emotional problems such as anxiety, depression or withdrawal may receive less attention than extreme behavioural problems, given their minimal impact upon other students or the teachers' ability to manage the class (Jull, 2008). The situation specificity of SEBDs, i.e. the symptomatology manifests differently across various settings (Norwich et al., 2002), suggests that the environmental context plays a significant role in SEBD's. Consequently, a lack of detection in the school setting is of considerable concern when problems are left untreated they become entrenched and subsequently require a broader and more flexible approach from professionals.

\section{The current study}

The current study sought to investigate the relationship between attribution style and behavioural problems, with the aim of identifying a potential avenue for in-school intervention. The sample included 71 students recruited from a school in South London to represent those receiving in-school behavioural support (identified with SEBD's) and those from the main school population (not identified with SEBD's). Based on previous research (Toth et al., 2002; Kee Tony, 2003; Rowe et al., 2006) the current study proposed several research questions:

1. Is there a relationship between attribution style and SEBD's?

2. Is there a difference between attribution styles for those who self-report SEBD's and are attending behavioural support, compared to those who are not?

3. Is there a difference between attribution styles for those self-reporting emotional problems compared to those who self-report behavioural difficulties?

4. Are there any gender differences?

It was hypothesised that there would be a positive relationship between negative attribution style and behavioural difficulties. It was further hypothesised that students 
attending the behaviour support programme would report greater conduct and hyperactivity problems than students recruited from the main school population (Collette \& Gimpel, 2004; Rowe et al., 2006). Students who reported using a more negative attribution style would also report greater emotional problems (Goodman, 1997). Finally, although emotional difficulties are known to exist in isolation, based on the findings of Rowe et al., (2006) it was hypothesised that those students receiving behaviour support and therefore identified with SEBD's would report the greatest emotional problems. Girls receiving behaviour support were expected to self-report the greatest emotional problems compared to all other groups.

\section{Method}

\section{Participants}

A total of 71 students from a South East London school, aged 13 to 16 years were recruited to participate in the study, of which 70 completed both questionnaires. The behavioural support group consisted of 26 students (13 male, 13 female) who attended behavioural support provisions within the school who had a mean age of 15.35 years $(S D=$ 0.91). No information was available to researchers regarding how long these children had been accessing behaviour support provisions. The comparison sample, the non-behavioural support group, consisted of 44 students (18 male, 26 female) attending mainstream lessons within the school. These students had a mean age of 14.98 years $(S D=0.60)$.

\section{Measures}

The Children's Attribution Style Questionnaire "CASQ" (Seligman, 1984) consists of 48 forced choice questions, designed for use with eight to 18 year olds (Gladstone \& Kaslow, 1995). The questionnaire is designed to assess how children explain positive and negative events through three dimensions of causality i.e. internal-external, stable-unstable, and global-specific. Children are provided a hypothetical scenario in which they must select one of two forced responses. For example, the question 'You get an A on a test' demands either the response 'I am smart', or 'I am good at the subject the test was in'. Half of the items on the CASQ refer to positive events and half to negative events. Scores for positive events and scores for negative events are totalled separately but can be compiled to create an overall attribution composite score. Attribution composite scores are calculated by subtracting the total negative score from the total positive score. A high attribution composite score is therefore indicative of a more positive attribution style.

The CASQ has been used extensively across the literature with psychometric validation indicating correlation coefficients above 0.66 for the total composite score, total positive and 
total negative scores. The CASQ has also indicated good stability across a six-month period with coefficients above 0.71 (Thompson et al., 1998).

The Strengths and Difficulties Questionnaire (Goodman, 1997) is a standardised and validated 25 item screening tool used to identify children aged three to 16 at risk of developing SEBD's. The current study utilised the self-report version of the tool. Five types of psychological behaviour are assessed each with a distinct clinical cut off:

1. Emotional symptoms, e.g. 'I worry a lot' (cut off $\geq 6$ ).

2. Conduct problems, e.g. 'I get very angry and often lose my temper' (cut off $\geq 4$ ).

3. Hyperactivity problems, e.g. 'I am restless, I cannot stay still for long' (cut off $\geq 6$ ).

4. Peer relationship problems, e.g. 'I have one good friend or more' (cut off $\geq 4$ ).

5. Pro-social behaviours, e.g. 'I often volunteer to help others' (cut off $\leq 5$ ).

Together the 25-items provide an overall total difficulties score where the clinical cause for concern is a score of 16 or above. The SDQ also includes supplementary questions relating to the child's behaviour and its impact upon activities in the home, classroom, friendships or their leisure time. Only participants who indicated that their difficulties might have an impact upon different aspects of their lives completed this supplementary section.

The self-reported SDQ has demonstrated good internal consistency for the total difficulties scale (cronbach's $\alpha=0.71$ to 0.82 ), in addition to cross informant agreement with the parent-reported SDQ (0.40 to 0.46). The self-reported SDQ has also demonstrated good validity with the Youth Self-Report (YSR; Achenbach, 1991) for total difficulties, and all five sub-scales (Becker, Hagenberg, Roessner, Woerner \& Rothenberger, 2004).

\section{Procedure}

Both students and parents were recruited via the school head teacher and were provided with information regarding the study. Students who provided consent to participate completed a questionnaire booklet containing the CASQ and SDQ detailed above within school hours. A female researcher was on hand during this period to explain the nature of the questionnaires and answer any questions. Biographic data, such as date of birth and school year, were also obtained.

\section{Design and analysis strategy}

Data was checked for normality prior to analysis. Relationships between the two dependant variables subscales (CASQ and SDQ) were analysed via Pearson's correlations. Furthermore, using a two-factor between subjects design multivariate ANCOVA was conducted to assess the differences between groups (behavioural support, non-behavioural 
support) on the 15 dependent variables; CASQ attribution style (internal-external, stableunstable, global-specific) and SDQ SEBD scores (emotion, conduct, hyperactivity, peer problems, pro-social behaviours and overall total dfficulties).

\section{Results}

Due to missing items on the questionnaires CASQ data was only available for 22 behavioural support students and 36 non-support students. Data for the SDQ was only available for 19 behavioural support and 31 non-support students. The means and standard deviations of each dependent variable for the remaining participants are presented in Table 1.

Table 1 here

\section{Relationships between SEBDs and attribution style}

Pearson's correlations were conducted to assess the relationship between SEBD's, using the six SDQ subscales (emotion, conduct, hyperactivity, peer problems and pro-social behaviours and total difficulties), and the three CASQ attribution style dimensions for the full sample (Table 2). Significant positive correlations were evident between the overall total difficulties subscale and the stability dimension attribution for negative events, $r(44)=.49, p$ $<0.01$, and the global-specific dimension attribution for negative events, $r(43)=.42, p<$ 0.01, suggesting that students who report more behavioural difficulties also report a greater negative attribution style. Further analyses of the relationships between the five remaining SDQ sub-scales and attribution style dimensions revealed significant positive correlations between hyperactivity and the internality dimension, $r(56)=.37, p<0.01$, the globalspecific dimension, $r(55)=.46, p<0.01$, and the stability dimension, $r(55)=.48, p<0.01$, of attribution for negative events. Similarly, significant positive correlations were found between conduct problems and the global-specific dimension, $r(52)=.30, p<0.05$, and the stability dimension, $r(52)=.45, p<0.01$, of attribution for negative events. No significant correlations were found between attribution style dimensions and emotional symptoms, peer problems or pro-social behaviour.

Table 2 here

\section{Differences in attribution style between groups}

\section{Attribution composite scores}


MANOVA analysis, presented in Table 3, indicated a statistically significant difference between groups (behavioural support, non-behavioural support) on the combined dependent variables, Wilks' Lambda $=0.75, F(6,47)=2.59, p<0.05, \eta p^{2}=0.25$. When the results for the dependent variables were considered separately, analysis revealed a significant difference between groups on the overall composite score for attribution style, $F(1,52)=8.03, p<$ $0.01, \eta p^{2}=0.13$ indicating that the behavioural support group reported a lower overall composite score, or a greater negative attribution style, compared to the non-behavioural support group.

Analysis revealed a statistically significant difference between groups for the total negative attribution scale, $F(1,52)=7.04, p<0.01, \eta p^{2}=0.12$, with the behavioural support group reporting greater use of negative attributions compared to the non-behavioural support group. There was no statistically significant difference between groups for the total positive attribution score, $F(1,52)=1.79, p>0.05 \eta p^{2}=0.03$, however, there was a trend for the behavioural support group to report less positive attributions than the non-behavioural support group.

\section{Global-specific attributions}

MANOVA analysis revealed no statistically significant differences between groups for the global-specific attribution dimension, $F(1,52)=1.33, p>0.05, \eta p^{2}=0.03$, however, there was a trend for the behavioural support group to make more global attributions for positive events than non-behavioural support. Similarly, there was also a trend for the behavioural support group to make more global attributions for negative events than the nonbehavioural support group. Again this difference was not statistically significant $F(1,52)=$ $2.71, p>0.05, \eta p^{2}=0.05$.

\section{Stable-unstable attributions}

A MANOVA revealed a statistically significant difference between groups on the stable-unstable dimension of attributions for negative events, $F(1,52)=6.49, p<0.01, \eta p^{2}=$ 0.11. Results indicated that students receiving behavioural support made more stable attributions for negative events compared to non-behavioural support students. Whilst there was no significant difference between groups for the stability of attributions for positive events, $F(1,52)=1.21, p>0.05, \eta p^{2}=0.02$, there was a trend for the behavioural support group to make less stable attributions for positive events than the non-behavioural support group.

\section{Internal-external attributions}


There was no statistically significant difference between groups on the internalexternal dimension of attributions for negative events, $F(1,52)=0.50, p>0.05, \eta p^{2}=0.01$. However, inspection of the means indicated a trend for students receiving behavioural support to report more internal- attributions for negative events compared to the other group of students. MANOVA analysis did reveal a statistically significant difference between groups for the internality dimension of positive events, $F(1,52)=8.16, p<0.01, \eta p^{2}=0.14$. Students receiving behaviour support self-reported less internality for positive events compared to the non-behavioural support students.

\section{Gender differences \& attribution style}

MANOVA analysis revealed a statistically significant difference between males and females on the overall composite score for attribution style, $F(1,52)=4.38, p<0.05, \eta p^{2}=$ 0.08. As Table 3 demonstrates, male students had a higher overall composite score compared to female students. There was no statistically significant difference between males and females on the total positive, $F(1,52)=2.70, p>0.05, \eta \mathrm{p}^{2}=0.03$, or total negative, $F(1,52)$ $=1.65, p>0.05, \eta p^{2}=0.08$, attribution style scores.

Table 3 here

MANOVA analysis also revealed a statistically significant interaction between the two independent variables, gender and group, along the global-specific attribution dimension, $F$ $(1,52)=4.91, p<0.05, \eta p^{2}=0.09$. To investigate this further an independent $t$-test was carried out with group as the independent variable and global-specific attribution style as the dependent variable. There was a significant gender difference for non-behavioural support group, $t(38)=2.43, p<0.05$. More specifically male non-behavioural support students made more global attributions for positive events compared to female non-behavioural support students. There was no significant gender difference for the behavioural support group, $t(21)$ $=-0.75, p>0.05$.

\section{Self-reported rates of social, emotional and behavioural difficulties (SEBDs)}

MANOVA analysis was conducted with group (behavioural support, non-behavioural support) and gender (male, female) entered as the independent variables and the six SDQ subscales (emotion, peer, conduct, hyperactivity problems, pro-social behaviours and total difficulties) entered as the dependent variables. Analysis indicated a significant effect for group on the combined dependent variables, Wilks' Lambda $=0.56, F(5,41)=6.33, p<$ $0.01, \eta p^{2}=0.44$. There was a significant main effect of group on total difficulties, $F(1,45)=$ 
17.11, $p<0.01, \eta p^{2}=0.28$, with behavioural support students self-reporting significantly more behavioural difficulties than students not receiving behavioural support.

Each of the five sub-scales of the SDQ were analysed separately. There was a significant difference between groups for conduct problems, $F(1,45)=16.06, p<0.01, \eta p^{2}$ $=0.26$, hyperactivity, $F(1,45)=27.07, p<0.01, \eta p^{2}=0.38$, and pro-social behaviour, $F(1$, $45)=5.73, p<0.05, \eta p^{2}=0.11$. Behavioural support students reported more conduct and hyperactivity problems and less pro-social behaviour, than non-behavioural support students (Table 1). There were no statistically significant difference between groups for either the emotion $F(1,45)=.48, p>0.05, \eta p^{2}=0.01$, nor peer problem subscales $F(1,45)=0.24, p$ $>0.05, \eta p^{2}=0.01$.

\section{Gender differences \& SEBDs}

Only one statistically significant difference between males and females were found for the five sub-scales of the SDQ. Female students reported more pro-social behaviours than male students $F(1,45)=8.40, p<0.01, \eta p^{2}=0.16$.

\section{Impact of SEBDs}

In the current study, only 40 of the 70 participants indicated that they had behavioural difficulties which affected their lives. When these scores were broken down into their constituent items, over half of the scores were 0 , further suggesting that the participants did not perceive their difficulties as having an impact on their lives. An independent samples $t$ test with group (behavioural support, non-behavioural support) as the factor was used to investigate the perceived impact of difficulties further. The $t$-test found that the behavioural support students reported a higher impact of their difficulties at home, $t(40)=3.67, p>.001$, in the classroom, $t(42)=3.16, p>.001$, and during leisure time, $t(39)=2.85, p>.01$, compared to the non-behavioural support students (Table 4).

Table 4 here

\section{Discussion}

Results from the current study indicated a significant effect of group for self-reported attribution style, with participants in the behavioural support group reporting a greater negative attribution style supporting the main hypothesis of the study. Furthermore, these 
findings are consistent with previous research which employed only self-report measures of behavioural difficulties (Rowe et al., 2006) and those which have examined relationships between attribution style and discipline problems (Kee Tony, 2003).

The differences between groups in applied attribution style were particularly evident in the internal-external and stability-instability domains, with participants in the support group making less internal attributions for positive events and more stable attributions (the cause is consistent across time) for negative events. Trends were also observed within the specificityglobality domain, with participants within the behavioural support group reporting more global attributions (the cause is consistent across events) for negative events. Those in the behavioural support group also reported attributions that showed trends towards being less stable for positive events and more internal for negative events. In support of the second hypothesis, and in line with previous research (Collett \& Gimpel, 2004; Rowe et al., 2006), all of these relationships were found to be significant for those self-reporting higher levels of conduct and hyperactivity problems. These results are particularly noteworthy as they further the findings of Rowe et al. (2006) and suggest that a persistent cognitive style is associated with a persistent experience of problem behaviour that is the same results will be obtained over time. The association in temporal duration of both negative attribution style and problem behaviour adds further support to the notion that the two are causally related; a reduction in one will result in a reduction in the other. Despite this, the current study is limited by using only one self-report measure of attribution style, during a programme designed to reduce problem behaviour. As a consequence it is not possible to establish whether a causal relationship exists and how this relationship could provide an effective target of intervention. This limitation could be easily addressed in future research by conducting a pre- and postintervention measure.

Also of interest is the lack of support for the hypothesis regarding emotional symptoms, with no differences found between males and females or support versus non-support group. This result fails to support previous findings (Lau et al., 2006; Rowe et al., 2006), and may be explained by one of two factors. Either the provision offered to those in the support group contains elements that are beneficial to emotional symptoms, or, emotional symptoms, such as depression, develop later on in life. Learned helplessness, on which attribution theory is built, suggests that the more one experiences a powerless situation the more powerless one feels. From a theoretical perspective the latter explanation is more probable. However, it is widely acknowledged that the prevalence of depression amongst young children is on the rise (NICE, 2013) and given that behavioural support groups are known to be effective it is suggested that the students in the current study maybe receiving support because their externalising behaviours maybe more of an issue. This idea is supported by the current findings that the sample reported more behavioural symptoms than emotional problems. The influence of support on emotional symptoms could be further understood by the inclusion of a pre-post intervention measure which may provide vital information to educators regarding the wellbeing of their students. Currently in the United Kingdom the Social and Emotional Aspects of Learning Programme (SEAL) is rolled out across approximately $90 \%$ of primary 
schools and $70 \%$ of secondary schools. The aim of the programme is to enhance children's social and emotional well-being, which will in turn increase effective learning for all students (Department for Education, 2010). Consequently, this programme offers the opportunity to address the limitations of this study.

The current findings may also provide support for previous research (Maras, 1996; Norwich et al., 2002; Rowe et al., 2006) that has demonstrated that emotional and behavioural problems share the same genesis. The finding that negative attribution style is associated with behavioural problems suggests that this, in addition to emotional difficulties, might be a symptom of the negative attribution style. In order to offer a holistic account of SEBD's one needs to consider other factors that may play a significant role in the acquisition of a negative attribution style, for example home and environmental conditions have been shown to be good proxies for later child development (Webster-Stratton, 1996) and may offer an alternative means of providing support and intervention to children and families most in need.

\section{Implications and conclusions}

Several important findings arise from the current study, one with theoretical implications and the other with applied connotations. Firstly, the higher rates of self-reported difficulties from those within the behaviour-support group compared to the non-behaviour support group suggest that either these adolescents have a more accurate understanding of their own behaviour, or that because they are receiving behaviour support at school they feel labelled with problematic behaviour and therefore act in accordance with this label. Rowe et al. (2006) suggest that relying on self-report measures alone may result in inflated associations between variables. If indeed these findings reflect the adolescents true understanding of their own behaviour then the current study provides evidence that selfreport may not only be a convenient measure for assessing behavioural difficulties but also a reliable one. Further research, using information acquired from multiple informants regarding adolescents behavioural problems is required to validate these findings.

Secondly, the finding that adolescents with greater behavioural difficulties utilise a more negative attribution style provides an avenue for attribution interventions to be applied. The results of this study, used in conjunction with the findings from Rowe et al., (2006) suggests that such interventions may be of particular benefit to those exhibiting conduct problems and/or hyperactivity as it was with these symptoms that the associations with negative attribution style were strongest.

Finally, the results from this study, along with a growing body of evidence (Rowe et al., 2006), suggest that the underlying attribution propensity for adolescents with behavioural difficulties or those experiencing emotional difficulties is shared. This suggests that attribution re-training has the potential to benefit both groups and provides an avenue worth pursuing to address both emotional and behavioural problems in young people. With SEBD's 
on the increase (Association of Teachers \& Lecturers, 2013) and with funds and time available to schools ever decreasing, finding a cost-effective route for intervention seems paramount and the current study adds support to the notion that interventions may offer this. 


\section{References}

Abramson, L. Y., Seligman, M. E. P, \& Teasdale, J. (1978). Learned helplessness in humans: Critique and reformulation. Journal of Abnormal Psychology, 87, 49-74.

Achenbach, T. M. (1991). Manual for Youth Self Report and 1991 profile. Burlington, VT: University of Vermont, Department of Psychiatry.

Anderson, J. A., Kutash, K., \& Duchnowski, A. J. (2001). A Comparison of the Academic Progress of Students with EBD and Students with LD. Journal of Emotional \& Behavioural Disorders, 9(2), 106-115. doi:10.1177/106342660100900205

Arnold, D. H. (1997). Co-occurrence of externalizing behavior problems and emergent academic difficulties in young high-risk boys: A preliminary evaluation of patterns and mechanisms. Journal of Applied Developmental Psychology, 18(3), 317-330.

Association of Teachers \& Lecturers. (2013). Disruptive behaviour in schools and colleges rises alongside increase in children with behavioural and mental health problems [Press release]. Retrieved from http://www.atl.org.uk/Images/disruptive-behaviour-on-rise.pdf

Beck, A. T (1967). Depression: clinical, experimental and theoretical aspects. New York: Harper \& Row.

Becker, A., Hagenberg, N., Roessner, V., Woerner, W., \& Rothenberger, A. (2004).

Evaluation of the self-reported SDQ in a clinical setting: do self-reports tell us more than ratings by adult informants? European Child \& Adolescent Psychiatry, 13, 11-24. doi: 10.1007/s00787-004-2004-4

Buchanan, A., Flouri, E., \& Ten Brinke, J. A. (2002). Emotional and behavioural problems in childhood and distress in adult life: risk and protective factors. Australian \& New Zealand Journal of Psychiatry, 36, 521-527. doi: 10.1046/j.1440-1614.2002.01048.x

Butkowsky, I. S., \& Willows, D. M. (1980). Cognitive-motivational characteristics of children varying in reading ability: events for learned helplessness in readers. Journal of Educational Psychology, 72, 408-422. doi: 10.1037/0022-0663.72.3.408.

Collett, B.R., \& Gimpel, G.A. (2004). Maternal and child attributions in ADHD versus non-ADHD populations. Journal of Attention Disorders, 7(4), 187-196. doi:10.1177/108705470400700401

Department for Education (2010). Social and emotional aspects of learning (SEAL) programme in secondary schools: national evaluation. (Research report DFE-RR049). 
Retrieved from www.gov.uk/government/publications/social-and-emotional-aspects-oflearning-seal-programme-in-secondary-schools-national-evaluation.

Gladstone, T. R. G., \& Kaslow, N. J. (1995). Depression and attributions in children and adolescents: A meta-analytic review. Journal of Abnormal Child Psychology, 23, 597606. doi: 10.1007/BF01447664

Goodman, R. (1997). The strengths and difficulties questionnaire: a research note. Journal of Child Psychology \& Psychiatry, 38, 581-586. doi: 10.1111/j.14697610.1997.tb01545.x

Hilsman, R., \& Garber, J. (1995). A test of the cognitive diathesis-stress model of depression in children: Academic stressors, attribution style, perceived competence, and control. Journal of Personality \& Social Psychology, 69, 370-380. doi: 10.1037/00223514.69.2.370

Hinshaw, S. P. (1992). Externalizing behavior problems and academic underachievement in childhood and adolescence: causal relationships and underlying mechanisms. Psychological Bulletin, 111(1), 127. doi: 10.1037/0033-2909.111.1.127

House of Commons Education Committee (2010). Behaviour and Discipline in Schools. First Report of Session 2010-11, Volume I: Report, together with formal minutes. Published on 3 February 2011 by authority of the House of Commons. London: The Stationery Office Limited. Retrieved from http://www.publications.parliament.uk/pa/cm201011/cmselect/cmeduc/516/516ii.pdf

Hutchings, J., Williams, M., \& Martin, P. (2011). Levels of behavioural difficulties among young Welsh schoolchildren. The Welsh Journal of Education, 15, 103-115.

Jull, S. K. (2008). Emotional and behavioural difficulties (EBD): the special educational need justifying exclusion. Journal of Research in Special Educational Needs, 8, 13-18. doi:10.1111/j.1471-3802.2008.00097.x

Kee Tony, T. S. (2003). Locus of control, attribution style and discipline problems in secondary schools. Early Child Development \& Care, 173(5), 455-466. doi:10.1080/0300443032000088203

Kurtović, A. (2012). Relationship between attributions for success and failure and selfesteem, hopelessness and depression in secondary school students. Croatian Journal of Education, 14(4), 771-797. 
Lau, J. Y. F., Rijsdijk, F., \& Eley, T. C. (2006). I think, therefore I am: a twin study of attribution style in adolescents. Journal of Child Psychology \& Psychiatry, 47(7), 696703. doi: 10.1111/j.1469-7610.2005.01532.x

Maras, P. (1996). "I'd rather have dyslexia": Perceptions of EBDs. Educational \& Child Psychology, 13(1), 32-42.

McEvoy, A., \& Welker, R. (2000). Antisocial Behavior, Academic Failure, and School Climate A Critical Review. Journal of Emotional \& Behavioral Disorders, 8(3), 130140. doi:10.1177/106342660000800301

National Insititute for Clinical Excellence (2013). Depression in young children: evidence update 42. NICE clinical guideline 28 'Depression in children and young people: identificatiom and management in primary, community and secondary care'.

Norwich, B., Cooper, P., \& Maras, P. (2002). Attentional and activity difficulties: findings from a national study. Support for Learning, 17(4), 182-186. doi: 10.1111/14679604.00262

Office for National Statistics. (2007). Three years on: survey of the development and emotional well-being of children and young people, London, ONS.

Reid, R., Gonzalez, J. E., Nordness, P. D., Trout, A., \& Epstein, M. H. (2004). A metaanalysis of the academic status of students with emotional/behavioral disturbance. Journal of Special Education, 38(3), 130-143. doi:10.1177/00224669040380030101

Rowe, R., Maughan, B., \& Eley, T. C. (2006). Links between antisocial behavior and depressed mood: The role of life events and attribution style. Journal of Abnormal Child Psychology, 34(3), 293-302.doi: 10.1007/s10802-006-9032-0

Seligman, M. P. (1984). Attribution style and depressive symptoms among children. Journal of Abnormal Psychology, 93, 235-238. doi: 10.1037/0021-843X.93.2.235

Thompson, M., Kaslow, N. J., Weiss, B., \& Nolen-Hoeksema, S. (1998). Children's attribution style questionnaire - revised: psychometric examination. Psychological Assessment, 10, 166-170. doi: 10.1037/1040-3590.10.2.166

Toth, S. L., Cicchetti, D., \& Kim, J. (2002). Relations among children's perceptions of maternal behavior, attribution styles, and behavioural symptomatology in maltreated children. Journal of Abnormal Child Psychology, 30, 487-500. doi: 10.1023/A:1019868914685

Tremblay, R. E., Masse, B., Perron, D., LeBlanc, M., Schwartzman, A. E., \& Ledingham, J. E. (1992). Early disruptive behavior, poor school achievement, delinquent behavior, 
and delinquent personality: longitudinal analyses. Journal of Consulting \& Clinical Psychology, 60(1), 64. doi: 10.1037/0022-006X.60.1.64

Weare, K., \& Gray, G. (2003). What works in developing children's emotional and social competence and wellbeing? (113pp). London, UK: Department for Education and Skills.

Webster-Stratton, C. (1996). Early onset conduct problems: does gender make a difference? Journal of Consulting \& Clinical Psychology, 64, 3, 540-551. doi: 10.1037/0022-006X.64.3.540

Weiner, B. (1979). A theory of motivation for classroom experiences. Journal of Educational Psychology, 71, 3-25. doi: 10.1037/0022-0663.71.1.3 
Table 1. Means and standard deviations for the two groups across all outcome variables using the CASQ and $S D Q$.

Behaviour Support Non-Support $M(S D)$ $M(S D)$

CASQ Positive:

Internal-External

$$
3.38(1.17)
$$

$(N=24$ v 36)

Stable-Unstable

$(N=22$ v 40)

Global-Specific

$(N=23$ v 40)

$11.41(2.52)$

$12.53(3.32)$

$(N=22$ v 36$)$

CASQ Negative:

Internal-External

$3.92(1.82)$

$3.66(1.63)$

$(N=24$ v 38)

Stable-Unstable

$2.64(1.50)$

$(N=23$ v 39)

$1.68(1.03)$

$(N=23$ v 39)

$10.83(3.24)$

$8.60(2.58)$

$(N=23$ v 35$)$

$S D Q$

Emotion

4.27 (2.66)

$4.03(2.46)$

$(N=22$ v 37$)$

Conduct

$5.00(1.95)$

$2.95(2.04)$

$(N=22$ v 37$)$

$6.35(2.55)$

$3.74(2.09)$

( $N=23$ v 39)

2.33 (1.96)

$2.15(1.58)$

Peer problems

$6.52(2.23)$

7.57 (1.69)

Pro-social

$18.95(4.74)$

$12.13(5.62)$

Total Difficulties

$(N=19$ v 31$)$

Note that sample sizes differ due to missing data 
Table 2. Pearson's correlations between SDQ and CASQ subscales.

\begin{tabular}{lcccccc}
\hline & $\begin{array}{c}\text { Globality } \\
\text { (positive) }\end{array}$ & $\begin{array}{c}\text { Globality } \\
\text { (negative) }\end{array}$ & $\begin{array}{c}\text { Stability } \\
\text { (positive) }\end{array}$ & $\begin{array}{c}\text { Stability } \\
\text { (negative) }\end{array}$ & $\begin{array}{c}\text { Internality } \\
\text { (positive) }\end{array}$ & $\begin{array}{c}\text { Internality } \\
\text { (negative) }\end{array}$ \\
\hline Emotional symptoms & -.14 & .12 & -.19 & .17 & .18 & .12 \\
Conduct problems & -.03 & $.30^{*}$ & -.13 & $.45^{* *}$ & -.19 & .23 \\
Hyper-activity & -.04 & $.46^{* *}$ & -.19 & $.48^{* *}$ & -.08 & $.37 * *$ \\
Peer problems & .03 & .10 & -.02 & .08 & .01 & -.07 \\
Prosocial behaviour & -.04 & .12 & .10 & -.01 & .11 & -.10 \\
Total difficulties & -.03 & $.42^{* *}$ & -.21 & $.49^{* *}$ & -.05 & .26 \\
\hline
\end{tabular}

$* * \mathrm{p}<0.001 * \mathrm{p}<0.05$ 
Table 3. Statistical comparisons of CASQ dimension scores between male and female students using MANCOVA.

\begin{tabular}{|c|c|c|c|c|c|c|}
\hline Dimension & Gender & $\mathrm{N}^{1}$ & Mean & $S D$ & $F$ & $p$ value \\
\hline \multicolumn{7}{|l|}{ Positive events } \\
\hline \multirow{2}{*}{ Internal-External } & Male & 26 & 4.04 & 1.25 & \multirow{2}{*}{.37} & \multirow{2}{*}{.55} \\
\hline & Female & 34 & 4.03 & 1.62 & & \\
\hline \multirow{2}{*}{ Stable-Unstable } & Male & 27 & 4.04 & 1.32 & \multirow{2}{*}{2.11} & \multirow{2}{*}{.15} \\
\hline & Female & 35 & 3.77 & 1.78 & & \\
\hline \multirow{2}{*}{ Global-Specific } & Male & 27 & 4.48 & 1.37 & \multirow{2}{*}{1.63} & \multirow{2}{*}{.21} \\
\hline & Female & 36 & 3.89 & 1.53 & & \\
\hline \multirow{2}{*}{ Positive Composite Score } & Male & 25 & 12.72 & 2.84 & \multirow{2}{*}{2.70} & \multirow{2}{*}{.12} \\
\hline & Female & 33 & 11.64 & 3.19 & & \\
\hline \multicolumn{7}{|l|}{ Negative events } \\
\hline \multirow{2}{*}{ Internal-External } & Male & 27 & 3.70 & 1.84 & \multirow{2}{*}{.08} & \multirow{2}{*}{.79} \\
\hline & Female & 35 & 3.80 & 1.61 & & \\
\hline \multirow{2}{*}{ Stable-Unstable } & Male & 27 & 2.78 & 1.48 & \multirow{2}{*}{1.54} & \multirow{2}{*}{.22} \\
\hline & Female & 35 & 3.31 & 1.68 & & \\
\hline \multirow{2}{*}{ Global-Specific } & Male & 27 & 2.42 & 1.48 & \multirow{2}{*}{.74} & \multirow{2}{*}{.39} \\
\hline & Female & 34 & 2.75 & 1.64 & & \\
\hline \multirow{2}{*}{ Negative Composite Score } & Male & 25 & 9.08 & 2.85 & \multirow{2}{*}{1.65} & \multirow{2}{*}{.21} \\
\hline & Female & 33 & 9.79 & 3.18 & & \\
\hline \multirow{2}{*}{ Overall Composite Score } & Male & 24 & 3.75 & 4.10 & \multirow{2}{*}{4.38} & \multirow{2}{*}{.04} \\
\hline & Female & 32 & 1.72 & 4.53 & & \\
\hline
\end{tabular}

${ }^{1}$ Note that sample sizes differ due to missing data 
Table 4. Means and standard deviations for impact of difficulties between SUPPORT GROUP and Non-SUPPORT GROUP students.

\begin{tabular}{llll}
\hline Impact of difficulties & Group & Mean & SD \\
\hline \multirow{2}{*}{ At home } & SUPPORT & .94 & .97 \\
& Non-SUPPORT & .16 & .37 \\
\multirow{2}{*}{ In the classroom } & SUPPORT & 1.05 & .91 \\
& Non-SUPPORT & .32 & .63 \\
\multirow{2}{*}{ During leisure activities } & SUPPORT & .42 & .71 \\
& Non-SUPPORT & .00 & .00 \\
\hline
\end{tabular}

